\title{
As dimensões escalares do Desenvolvimento Regional: o caso da evolução do turismo em Gramado-RS
}

\author{
Roger Pierre Vidal ${ }^{1}$ \\ Daniela Burkhard ${ }^{2}$ \\ Roberto Tadeu Ramos Morais ${ }^{3}$
}

\section{Resumo}

Este trabalho inicialmente apresenta uma revisão conceitual a ser utilizada para analisar a evolução histórica do território de Gramado, desde os anos 1930 até 2008, tendo como ênfase o desenvolvimento do território no período de integração local e a pressão que a globalização exerceu sobre o desenvolvimento do município. O principal objetivo do estudo foi analisar as macrodecisões e as suas influências no processo de desenvolvimento do município de Gramado, no período de mais de setenta anos, tendo como foco descrever o processo de evolução do espaço econômico do município. O presente artigo fundamenta-se numa análise qualitativa, baseada em dados secundários, para descrever a evolução histórica do município foram realizadas pesquisas bibliográficas e documentais. Conclui-se que os impactos das macrodecisões para a evolução do Município de Gramado modificaram a economia e resultaram na geração de diversas alternativas econômicas desenvolvidas na cidade e alicerçadas no setor de turismo e em outras que ainda podem ser grandes apostas econômicas identificadas no estudo.

Palavras-chave: Território. Territorialidade. Espaço. Gramado.

\section{Abstract}

Firstly this paper presents a conceptual review to be used to analyze the historical evolution of the territory Lawn, from the 1930s until 2008, with the emphasis on the development of the territory in the period of local integration and the pressure that globalization has had on the development of municipality. The main objective of the study was to analyze the macro decisions and their influences on the development of the municipality of Gramado process, the period over seventy years, focusing on describing the process of evolution of the economic space of the city. This article is based on a qualitative analysis based on secondary data, to describe the historical evolution of the city bibliographic and documentary surveys were conducted. It is concluded that the impacts of macro decisions for the evolution of the city of Gramado changed the economy and resulted in the generation of various economic

\footnotetext{
${ }^{1}$ Mestrando do Programa de Pós-Graduação em Desenvolvimento Regional (PPGDR) das Faculdades Integradas de Taquara - FACCAT. rogerpvidal@hotmail.com

${ }^{2}$ Mestranda do Programa de Pós-Graduação em Desenvolvimento Regional (PPGDR) das Faculdades Integradas de Taquara - FACCAT. dfxconsultoriampe@gmail.com

${ }_{3}^{3}$ Professor Doutor do Programa de Pós-Graduação em Desenvolvimento Regional (PPGDR) das

Faculdades Integradas de Taquara - FACCAT. r.roberto.morais@gmail.com
} 
alternatives developed in the city and grounded in the tourism sector and others that may still be large economic stakes identified in the study.

Keywords: Territory. Territoriality. Space. Gramado City.

\section{Introdução}

O desenvolvimento do espaço, segundo Santos (2001), forma-se através das interações entre os objetos e o sistema de ações. A globalização trouxe novas formas espaciais, onde atores hegemônicos intervêm cada vez mais nos espaços, alterando e reordenando os territórios e isso gerou uma perda das identidades locais. A globalização trouxe novas formas espaciais, onde atores hegemônicos intervêm cada vez mais nos espaços, alterando e reordenando os territórios e isso gerou uma perda das identidades locais.

Nesse sentido, a evolução da cidade de Gramado como objeto de um estudo que analisa as hierarquias dos conjuntos espaciais justifica-se em função da história da cidade de Gramado como exemplo das influências das escalas espaciais. A cidade de Gramado é especializada no setor turístico, com uma organização espacial e uma trajetória de concentração geográfica e de ações nas atividades turísticas territoriais resultantes de relações sociais locais. Gramado em seu processo histórico passou por transformações que levaram a cidade a criar o que hoje condiciona o município a ser um polo turístico do Rio Grande do Sul.

O presente artigo utiliza a pesquisa qualitativa e o estudo exploratóriodescritivo, para descrever os aspectos ligados à formação história do recorte espacial de Gramado, localizado a $115 \mathrm{~km}$ de distância da cidade de Porto Alegre capital do estado do Rio Grande Sul, e sua trajetória para tornar-se um polo turístico, através da evolução dos espaços e suas relações. Busca-se através de uma abordagem qualitativa com base em procedimentos bibliográficos e documentais fazer uma discussão sobre conceito de território e o desenvolvimento dos espaços proposto por Hedrich, (2004) e Santos (2001). Através de análise documental em arquivos e periódicos sobre 0 assunto, assim como pesquisa com dados secundários foi descrita a evolução espacial de Gramado. 


\section{As dimensões escalares do Desenvolvimento Regional}

Para pensar em desenvolvimento local é preciso entender alguns fatores de contextualização sobre o tema, considerado importante na atualidade, no qual todos os pensamentos econômicos estão voltados para o território e sua divisão espacial. Nesse sentido serão apresentadas a seguir as noções de Desenvolvimento Regional, espaço, território e territorialidade.

Desenvolvimento Regional pode ser considerado um "[...] processo de mudanças sociais e econômicas que ocorrem em uma determinada região. No qual pode ser delimitado [...] através de diferentes aspectos: geográficos, administrativos, econômicos, físico-naturais, culturais, políticos, etnográficos, entre outros" (SIEDENBERG, 2006, p. 71).

Espaço pode ter vários sentidos, mas quando se trata da forma de desenvolvimento local, esta palavra, descreve a materialização geográfica dos processos e as atividades envolvidas na produção das condições de vida da sociedade. Para Santos (2001) é preciso reconhecer o espaço como um campo de relações, quando se trata de "coisas ou seres" que permanecem em determinado local e podem ser conferidos. Ainda, o autor completa que os espaços agregam a todos, com múltiplas possibilidades, que são alternativas diferentes de uso do espaço.

\footnotetext{
O conceito expresso por Milton Santos (1997) no qual o espaço geográfico constitui 'um sistema de objetos e um sistema de ações' que: é formado por um conjunto indissociável, solidário e também contraditório, de sistemas de objetos e sistemas de ações, não considerados isoladamente, mas como um quadro único na qual a história se dá. No começo era a natureza selvagem, formada por objetos naturais, que ao longo da história vão sendo substituídos por objetos fabricados, objetos técnicos, mecanizados e, depois cibernéticos fazendo com que a natureza artificial tenda a funcionar como uma máquina (SUERTEGARAY, 2001, p. 2).
}

O mesmo autor afirma que o espaço é uma criação dos indivíduos através das ações e nesse contexto os espaços são criados e se desenvolvem através do tempo com interação entre indivíduo e natureza e também na influência mútua entre as próprias pessoas ao longo da história.

Nessa forma o espaço comparece no estudo da dimensão espacial do desenvolvimento, sendo entendido como a palavra que aponta e descreve a 
materialização geográfica dos processos e atividades envolvidas na produção e reprodução das condições de vida da sociedade. Então, o espaço para uma análise sobre a ótica do desenvolvimento local pode ser definido como a vida em sociedade e espelha aspectos centrais do funcionamento desta. Lins (2009) mostra que o espaço tem uma forma muito complexa na atualidade.

\footnotetext{
Uma sociedade capitalista moderna, que apresenta uma enorme gama e complexidade de fluxos e de "cristalizações" geográficas - fábricas, infraestrutura, etc.-, exibe formas espaciais igualmente complexas, multi estratificadas ao nível das atividades econômicas, das áreas urbanas e suas superfícies de abrangência e das interligações multiescalares (escalas regionais, nacionais, internacionais) que as envolvem (LINS, 2009. p. 12).
}

O espaço no desenvolvimento vincula-se a ideia de que, ao produzir as formas para a sua sobrevivência os indivíduos, por meio das interações, criam objetos como, por exemplo; áreas de plantio, fábricas, estradas, portos etc., que se distribuem na superfície terrestre. Esta ação implica transformar a natureza selvagem e disso resultando o surgimento de uma natureza artificial. Quando é produzida a natureza artificial cria-se uma relação social, e o resultado desta relação, segundo Lins (2009), é a organização espacial da sociedade. Então, além de ser reflexo do funcionamento da sociedade e traduzir as relações sociais, 0 espaço é também determinante dessas relações sociais.

Com o desenvolvimento das relações sociais surgem as territorialidades, pois através da organização espacial os atores sociais em um determinado espaço geográfico, alinham-se a um sentimento de sobrevivência do todo, mesmo com a diversidade dos interesses ali presentes. Conforme Heidrich (2004) o território nasce das relações dos indivíduos e o espaço, sendo que a organização espacial está ligada ao sentimento de territorialidade. Neste sentido há uma ligação indissociável entre espaço e território no desenvolvimento local, pois segundo o autor ter consciência de espaço refere-se a um sentimento de pertencer a um território, é criar identidade e relaciona-se com os interesses de determinado espaço, isto vai criar os territórios, pois para Heidrich (2004) a territorialidade cria o território.

Brandão (2004), afirma que o território é a construção social conflituosa, é construído através da interação dos agentes locais, numa intensa relação de poder, então quando se fala em desenvolvimento local, o território não pode ser confundido com um sitio fixado. O território nasce das relações sociais em uma cada localização 
geográfica, onde os agentes sociais fixam-se e constroem escalas de cooperação e competição.

\section{Integração nacional e o processo de globalização}

Quando a organização espacial tem seu completo desenvolvimento das relações sociais se estabelece a condição territorial, sendo que neste momento passa a existir a manifestação generalizada de um poder, onde Segundo Heidrich (2004) cria-se o território estatal-nacional que é o que mais visivelmente reúne todo esse desenvolvimento.

No Estado moderno, com o desenvolvimento das relações sociais, surge o território nacional, e isto consiste em distinguirem-se as sociedades umas das outras, e está distinção também vai acontecer internamente dentro do território, segundo Heidrich, (2004), se criam configurações diferenciadas espacialmente, sendo o Estado responsável por formar a construção do coletivo que permita cada individuo identificar-se com coletivo. Deste modo os interesses das regiões são frutos das relações de poder, neste sentido os espaços regionais, estão ligados aos interesses de um espaço maior. Brandão sintetiza melhor essas articulações para o Desenvolvimento Regional:

\footnotetext{
Cada problema tem a sua escala espacial específica. É preciso enfrentá-lo a partir a articulação dos níveis de governo e das esferas de poder pertinentes àquela problemática específica. Além das articulações intraregionais é importante ampliar seu raio político de manobra a fim de negociar sua inserção inter-regional. Explicitar os conflitos de interesse em cada escala e construir coletivamente a contratualização das políticas públicas (BRANDÃO, 2004, p. 61).
}

Brandão (2004) afirma ainda que as escalas, níveis e esferas devem ser tratadas de forma criativa, lançando mão de variados instrumentos, politizando as relações, construindo cidadania e buscando combater as coalizões conservadoras.

Neste contexto, o território tem diferentes níveis de análise, para entender nacional e seus conjuntos espaciais, é preciso entender o conjunto como um todo, e as suas articulações em todas as esferas dos conjuntos para assim entender 0 desenvolvimento local. Não se pode entender o desenvolvimento local apenas em 
seu conjunto espacial local, pois o desenvolvimento é feito através da articulação nos diferentes níveis escalares.

A globalização ${ }^{4}$ foi um processo que reestruturou o mercado mundial através das novas tecnologias, onde tudo e todos estão integrados, esta conexão se materializou de forma desigual no decorrer das ultimas décadas, provocando um aumento maior dos diferenciais inter-regionais, salientando uma profunda desigualdade. A globalização quebrou o sistema de integração até então existente, onde a cooperação econômica local e nacional existente perdeu força para uma integração global, sendo que as regiões mundiais mais fortes economicamente saíram na frente. As regiões que antes eram prósperas acabaram sendo condenadas a pobreza, através da pressão pela integração total, conforme descreve Heidrich (2004, p. 47):

\footnotetext{
Este processo tem efeito direto para o próprio sistema, pois o aumento da concorrência intercapitalista também faz concorrer entre si os sistemas nacionais e regionais de normatizações. Funciona como "pressão" para a unificação, para que as relações comerciais ocorram com as mesmas regras. [...]. Desta forma, a globalização, vista como a etapa atual de um processo maior de continua integração em âmbito mundial, interfere também nas demais escalas das integrações sócias espaciais, como o cotidiano de comunidades locais, sociedades regionais e nacionais.
}

A globalização tornou-se uma forma de pressão para unificação, afetando inevitavelmente o funcionamento dos Estados Nacionais e a viabilidade do sistema integração local. Tomazzoni (2009), afirma a nova dimensão de território das cadeias globais na atualidade; a noção de território transcende o aspecto geográfico e abrange pontos distantes, ligados por formas e processos sociais. Esse espaço econômico é organizado hierarquicamente, com seu comando concentrado em cidades mundiais, na qual a tecnologia da informação tem papel relevante. As palavras de Heidrich (2004) exemplificam bem o que ocorreu com a globalização, isto é, teve uma ruptura da solidariedade local construída no Estado moderno, onde as novas tecnologias substituem continuidade física pelo tempo compartilhado no espaço de fluxos.

\footnotetext{
${ }^{4}$ A globalização é um dos processos de aprofundamento internacional da integração econômica, social, cultural, política, que teria sido impulsionado pelo barateamento dos meios de transporte e comunicação dos países no final do século XX e início do século XXI.
} 


\title{
4 A atividade de turismo e a estruturação dos centros turísticos
}

O turismo, segundo o autor Rose (2002), é uma atividade econômica do setor terciário e consiste em um conjunto de serviços que se vende ao turista. Estes serviços estão necessariamente inter-relacionados de tal forma, que a ausência de um deles dificulta e até inviabiliza a venda ou a prestação de todos os outros; possuem peculiaridades rigidamente determinadas para as quais se traslada 0 turista, ainda que a comercialização possa realizar-se no local de produção ou fora dele, ou seja, no ponto de origem da demanda. A diferença marcante é que na atividade turística não se realiza uma distribuição física do produto, pois é o consumidor que se desloca até a fonte de produção.

No entanto, o conceito de turismo, atualmente adotado pela Organização Mundial do Turismo - OMT pode ser verificado na obra do autor De La Torre (2003, p. 24), que descreve que:

\begin{abstract}
O turismo é um fenômeno social quer consiste no deslocamento voluntário e temporário de indivíduos ou grupos de pessoas que, fundamentalmente por motivos de recreação, descanso, cultura ou saúde, saem de seu local de residência habitual para outro, no qual não exercem nenhuma atividade lucrativa, nem remunerada, gerando múltiplas inter-relações de importância social, econômica e cultural.
\end{abstract}

Sento o turismo hoje, considerado a principal atividade econômica, a maior "indústria" existente, superando setores tradicionais da economia, como a indústria automobilística, eletrônica e petrolífera. O setor tornou-se um grande gerador de postos de trabalho, produzindo 192 milhões de empregos diretos e um número incalculável de atividades paralelas (OLIVEIRA, 2001).

Já o espaço turístico é conseqüência da presença e distribuição territorial dos atrativos turísticos, que são a matéria prima do turismo, no entanto uma característica física básica é que os atrativos dificilmente se tocam, refletindo assim sua descontinuidade (BOULLÓN, 2002).

Conforme Boullón (2002), o espaço turístico é classificado em uma hierarquização espacial que vai desde o que ele designa como uma zona turística (a maior área em que se pode dividir um país), até o núcleo turístico (a menor unidade espacial consistindo em espaço com potencialidades turísticas, porém, ainda não interligado com os demais elementos do sistema). 
O mesmo autor ainda descreve que o centro turístico corresponde a todo conglomerado urbano que, em seu próprio território ou área de influência, possui atrativos turísticos, de tipo e hierarquia suficientes, para motivar uma viagem. Para permitir viagens de ida e volta no mesmo dia, possui um raio de influência calculado em duas horas de distância-tempo, correspondendo ao caminho que pode ser percorrido por um ônibus de turismo (BOULLÓN, 2002).

Portanto, esse raio é variável, depende das condições das estradas e da topografia, devendo ser utilizado como critério, não como medida exata. Para ser considerado como centro turístico é importante que seu empreendimento turístico conte com: hospedagem, alimentação, entretenimento, agências de viagem de ação local, informações turísticas sobre os atrativos e instalações locais, comércio turístico, posto telefônico, correios, telégrafos, sistema de transporte interno organizado, conectando o centro aos diversos atrativos existentes em sua área de abrangência, como também, conexão com os sistemas de transporte externo, em âmbito nacional, internacional, regional ou local, conforme a hierarquia do centro. De acordo com a função que desempenham podem ser classificados em centros turísticos de distribuição, de estada, de escala e de excursão. Os corredores turísticos, de acordo com a função que desempenham no sistema turístico podem ser classificados como de traslado ou de estada. Os corredores de traslado constituem-se da rede de estradas que interligam os diversos atrativos turísticos da região, como também, os centros turísticos. São os caminhos utilizados pelos turistas em seus deslocamentos. Já os corredores de estada, se configuram em superfícies alongadas, em geral paralelas às costas de mares, rios ou lagos, e funcionam como uma combinação entre centro e corredor turístico (BOULLÓN, 2002).

Pode-se compreender que para a regionalização do turismo, torna-se imprescindível o levantamento da infraestrutura turística, feito através do inventário turístico, conforme ensina Petrocchi (2001), como também a localização espacial desses atrativos, para que se consiga delimitar a região turística como demonstrou Boullón (2002). Eles também alertam para a necessidade de uma abordagem sistêmica do turismo.

Ainda, com relação ao turismo, analisam-se as relações entre ele (o turismo) e o "território", que ocorrem de acordo com três tipos de situação, conforme demonstra Knafou et al. (2001). Na primeira, os territórios sem turismo, pois no 
mundo globalizado, através das várias possibilidades de transporte, os turistas podem visitar qualquer lugar, isso não significa que, o local receptivo da visitação, seja território turístico; em segundo lugar, o turismo sem território, onde o turismo não procede de iniciativa de turistas, ou seja, realizado em lugares equipados, quase que completamente indiferente à região que o acolhe e onde a extensão planejada nada mais é do que um espaço-receptáculo. Neste caso, o planejamento do território é apenas um planejamento do espaço, no qual o turismo constitui um princípio de organização, reduzido a uma atividade econômica, criadora de empregos e lucrativa; finalmente, numa terceira situação, os territórios turísticos, ou seja, os inventados e produzidos pelos turistas, mais ou menos retomados pelos operadores turísticos e pelos planejadores. Neste caso o espaço deve ser planejado juntamente com a comunidade.

Para um melhor entendimento e aprofundamento das questões levantadas no parágrafo anterior, podem-se utilizar as reflexões de Kripendorf (2001) o qual fez uma análise sociológica do turismo, prevendo uma série de conflitos entre as populações autóctones e os turistas. Argumenta o autor que quando a localidade passa a ser turística pelo interesse do visitante, desencadeia uma série de ações desordenadas para criar a infraestrutura necessária ao atendimento do turista, sem levar em conta, na maioria das vezes, os interesses da comunidade local. A vinda dos turistas promove mudanças na cultura local, a partir da adoção de costumes externos a região nem sempre interessantes, como: uso de drogas e estilos de vida. Outro ponto levantado por Kripendorf (2001) é a introdução do turismo a partir de instituições externas, as quais inserem estruturas com qualidade para receber 0 turista, contrastando com a qualidade e o estilo de vida dos residentes, os quais são chamados somente para trabalhos braçais ou apresentações culturais, não havendo integração entre as comunidades locais e seus visitantes.

Trata-se do que Knafou et al. (2001) denominou turismo sem território, e que Kripendorf (2001) chama de enclaves nos locais de destino, pois não trazem benefícios em termos de melhoria de renda às populações locais, como também não permitem uma visão completa das condições de vida do país visitado, por parte do turista. Finalmente, o terceiro ponto, trata do planejamento do turismo a partir do interesse da comunidade local, baseando-se na existência de atrativos, porém sem 
levar em conta o interesse do turista, ou seja, da demanda, ocorrendo o desenvolvimento de produtos turísticos deficientes.

Um determinado lugar para se tornar um destino turístico deve possuir elementos que motivem um deslocamento temporário das pessoas, nesse sentido o atrativo turístico é a matéria-prima, ou seja, os recursos naturais, culturais, sociais e tecnológicos passam a ter importância crucial. Eles podem tanto ter capacidade própria ou em combinação com outros para atrair os turistas (RUSCHMANN, 1999).

A mesma autora, com base em ampla revisão bibliográfica, demonstra que os atrativos turísticos devem ser classificados de acordo com o seu grau de atratividade em quatro níveis hierárquicos, que são: a) Hierarquia 03: atração excepcional, altamente significativa para o mercado turístico. É capaz, por si só, de motivar uma grande corrente de turistas; b) Hierarquia 02: atração com aspectos excepcionais, capaz de motivar uma corrente de turistas nacionais ou estrangeiros, por si própria ou em conjunto com outras atrações; c) Hierarquia 01: atração com alguns aspectos chamativos, capaz de interessar turistas que vierem de longe para a região, por outras motivações turísticas, ou capaz de motivar correntes turísticas locais; d) Hierarquia 00: atração sem méritos suficientes para ser incluída nas hierarquias anteriores, porém, faz parte do patrimônio turístico como elemento que pode complementar outro de maior interesse no desenvolvimento de complexos turísticos. Entre outros efeitos econômicos de destaque, o turismo também proporciona a geração de rendas para o setor público representada por impostos diretos e indiretos incidentes sobre a renda total gerada no âmbito do sistema econômico, bem como seu caráter de estimulador do processo de abertura da economia.

\section{Evolução turística de Gramado e sua integração local e global}

É preciso entender e analisar as hierarquias dos conjuntos espaciais, sendo que a historia da cidade de Gramado um bom exemplo das influências das escalas espaciais, A cidade teve grande salto no desenvolvimento quando governo Federal decidiu trazer o Trem até a cidade, a linha da locomotiva ligava Porto Alegre a Gramado. A chegada do trem à região teve um grande impacto nas relações econômicas, por que ligaram o município as principais cidades da época. Com esta grande mudança, a atividade econômica começou a variar, surgindo um comércio 
mais diversificado, e proporcionando a chegada de professores, médicos, entre outros profissionais que adotaram o município como sua nova morada.

Segundo Daros (2012, p. 2):

\begin{abstract}
Todos os caminhos e povoamentos surgidos na serra gaúcha, sem dúvida, têm uma característica comum: estabelecer um mercado intermediário entre Porto Alegre, São Leopoldo, Santo Antônio da Patrulha, os Campos de Cima da Serra e os caminhos que levavam ao norte, para Sorocaba, no Estado de São Paulo, e para um comércio maior, especialmente, o comércio muar.
\end{abstract}

Neste período Gramado vai ganhando forma e tamanho de uma cidade turística, devido as suas belezas naturais, os primeiros a visitarem Gramado eram chamados de veranistas, pois visitavam a cidade nos meses de verão, entre dezembro e fevereiro, buscando as temperaturas mais amenas. Os principais atrativos naturais da época eram as cascatas existentes, como a Cascata Véu de Noiva e Cascata dos Narcisos ${ }^{5}$. Neste período os turistas não vinham para Gramado no inverno devido a falta de estrutura local. As macrodecisões de levar o trem a Gramado tiveram como resultado a consolidação da cidade como uma cidade turística, sendo que este período foi muito próspero para Município. Geralmente as pessoas que moravam na capital tinham Gramado como lugar para descansar durante os finais de semana, além de servir como "colônia de férias" para os metropolitanos (DAROS, 2012).

Em meados de 1950 com as macrodecisões, as condições de prosperidade mudariam, por que a atividade de veraneio na Serra sofre uma redução. O setor de turismo foi fortemente afetado pelas decisões em escalas superiores, o mesmo autor evidencia dois grandes motivos que levaram a redução de visitantes a Gramado. 0 primeiro foi o surgimento do veraneio no litoral, quando nascem balneários turísticos junto ao litoral norte Gaúcho. O segundo foi o processo iniciado pelo Governo Federal de troca da matriz de transporte ferroviário para a matriz de transporte rodoviário. Neste sentido a cidade teve uma queda na atividade turística.

Neste período as macrodecisões voltam-se para industrialização, surge em Gramado o setor calçadista que conseguiu absorver os empregos e as demandas do

\footnotetext{
${ }^{5}$ Narciso é escrita no singular, pois se refere à família Narciso, que tinha terras aos arredores da cascata, não se relacionando a flor narciso.
} 
turismo, assim a cidade continuou a crescer, com uma tendência na especialização do setor calçadista.

$\mathrm{Na}$ década de 50, a cidade começou a expandir a sua economia. Conforme Macadar e Macadar (2013) as fábricas de calçados começaram a surgir, dando destaque a E. Volk \& Filhos (1953), empresa que anos mais tarde ficou conhecida nacional e internacionalmente como Ortopé, a Calçados Samore (1956) e Indústria de Calçados Rissi empresas que tinham seu nome conhecido dentro e fora do Brasil (1994), também ajudaram no desenvolvimento do município, garantindo empregos aos moradores e acelerando a economia.

A cidade caminhava para a industrialização, com a empresa de calçados Ortopé consolidando-se como uma empresa de grande porte no ramo calçadista brasileiro. O grupo Ortopé se destacou pela atuação no segmento de calçados infantis, conseguindo a liderança do mercado nacional, chegando ao ano $95 \mathrm{com}$ a fatia do mercado nacional de 38\% (Macadar; Macadar, 2013), Tabela 1.

\section{Tabela 1 - Capacidade nominal brasileira de tênis infantil - 1995}

\begin{tabular}{|l|r|r|}
\hline Empresas & Pares/Dias & $\%$ \\
\hline Ortopé & 22.500 & $38,8 \%$ \\
\hline Brochier & 14.000 & $24,1 \%$ \\
\hline Bical & 12.000 & $20,7 \%$ \\
\hline Popi & 9.500 & $16,4 \%$ \\
\hline Total & 58.000 & $100,0 \%$ \\
\hline
\end{tabular}

Fonte: Oliveira e Medeiros (1995)

O autor afirma que a Ortopé calçados correspondia à quinta empresa que mais faturava no Brasil no setor calçadista, portanto, Gramado tinha uma economia industrial forte. A Tabela 2 confirma que município tinha o setor de calçados como uma unidade motriz, por que a industrial correspondia a 57, 35\% e o setor de serviços a $39 \%$ do valor agregado bruto no ano 1990, segundo Perroux (1967) a unidade motriz econômica pode ser uma empresa, um conjunto de empresas, um indústria, ou conjunto de indústria que tenha a capacidade de gerar um resultado o econômico positivo, no sentido de transformar as estruturas locais através do crescimento do produto real global do conjunto considerado. 
Tabela 2 - Produto Interno Bruto (PIB) a preços correntes -1990

\begin{tabular}{|l|l|r|}
\hline \multicolumn{3}{|c|}{ Valor Adicionado Bruto a Preços Básicos 1990} \\
\hline Agropecuária & $1990-(\mathrm{Cr} \$$ mil $)$ & 215.387 \\
\hline Comércio & $1990-(\mathrm{Cr} \$$ mil $)$ & 516.480 \\
\hline Demais Serviços & $1990-(\mathrm{Cr} \$$ mil $)$ & 2.405 .925 \\
\hline Indústria & $1990-(\mathrm{Cr} \$$ mil $)$ & 4.218 .932 \\
\hline Total & $1990-(\mathrm{Cr} \$$ mil $)$ & 7356724 \\
\hline Total dos Serviços & $1990-(\mathrm{Cr} \$$ mil $)$ & 2.922 .405 \\
\hline
\end{tabular}

Fonte: Adaptado de FEE (1990).

O conflito em torno da atividade econômica calçadista trouxera para a Cidade uma especialização neste setor, isto teve pontos positivos, pois influenciou na decisão de investimento na atividade econômica ligada ao setor de calçado naquele período, sendo que várias atividades econômicas ligadas ao setor instalaram-se na cidade devido à unidade motriz.

O setor de calçados ditou o crescimento da cidade até os anos 1990, Gramado teve um período muito próspero de um elevado crescimento econômico, quando os interesses nacionais estavam voltados para o mercado externo, em um período de industrialização nacional, mas quando começou o processo da globalização e por consequência uma integração do mercado global, a atividade econômica que era próspera, passou a ter uma integração máxima com todos os mercados, a globalização gerou forte concorrência em todo o sistema capitalista, trazendo um efeito muito negativo para o desenvolvimento do setor de calçados.

Com a abertura da economia brasileira e o plano real ${ }^{6}$ a partir do ano de 1994, o município de Gramado que tinha crescimento contínuo no setor de calçados teve seu processo de desenvolvimento novamente interrompido por fatores externos e decisões nas esferas hierárquicas escalares superiores. O resultado em todas as atividades econômicas ligadas ao setor calçadista foi falência generalizada. Neste caso o setor ficou muito fragilizado com a competitividade internacional gerando uma

\footnotetext{
${ }^{6}$ Plano Real foi um programa brasileiro com o objetivo de estabilização e reformas econômicas, iniciado oficialmente em 30 de julho de 1994 com a publicação da medida provisória no 434 no diário oficial da união. Tal Medida Provisória instituiu a Unidade Real de Valor (URV), estabeleceu regras de conversão e uso de valores monetários, iniciou a desindexação da economia, e determinou o lançamento de uma nova moeda, o Real.
} 
crise em todas as regiões que tinham como a principal atividade econômica à indústria calçadista, gerando estagnação em um setor que vinha crescendo.

A liderança de mercado da Ortpé sofreu duras perdas no final da decada de 90. Após a implantação do plano real, e com a abertura das importação asiáticas, o ambiente competitivo se transformou significativamente em um curto espaço de tempo, alterando o padrão competitivo vigente na industria. Destaca-se nesse período a necessidade maior formalização das relações econômicas entre governo e empresas (MACADAR; MACADAR, 2013, p. 202).

Em Gramado o turismo foi uma alternativa para absorver gradualmente muita gente desempregada do setor de calçados e movimentar a economia, sendo uma alternativa para continuar o crescimento e desenvolvimento da cidade, após a dinâmica da indústria dos calçados que durou até os anos 1990. O processo de globalização reestruturação econômica brasileira, tornou mais complexa as relações quebrando a integração local existente, ouve uma perda no dinamismo em alguns setores econômicos.

Nos anos 1990 as macrodecisões voltaram-se para o setor de turismo e, assim, Gramado conseguiu articular e alinhar suas políticas em torno desta atividade econômica. Conforme demonstra Cruz (2000) a partir dos anos 1990 o governo federal passou a incentivar o turismo, através da Política Nacional de Turismo (PNT), instituída durante o primeiro mandato do presidente Fernando Henrique Cardoso. Com os novos parâmetros das macrodecisões voltadas para políticas de desindustrialização e fortalecimento da economia interna, o turismo surge como uma alternativa para Gramado, o território passa apreender e transformar os espaços em um território turístico.

A Tabela 3 evidencia a transformação que a economia de Gramado teve nos últimos anos (2005-2008), pois em comparação com a Tabela 2 do ano de 1990, fica evidente que o setor de serviços torna-se o mais importante da economia de Gramado, o setor passou a corresponder por $61 \%$ do Valor Adicionado Bruto (VAB7) no ano 2008. Percebe-se que a média do VAB de serviços é maior que a média dos VAB de Agropecuária e Indústria. Isto se deve ao fato de Gramado possuir sua base

\footnotetext{
${ }^{7}$ Valor agregado bruto (VAB) é o valor bruto da produção de cada unidade produtiva descontado do valor dos bens e serviços adquiridos de outras unidades produtivas e transformados integralmente ao longo do processo de produção.
} 
econômica atual no setor de turismo, sendo esta a estrutura predominante no setor de serviços.

Tabela 3 - Produto Interno Bruto (PIB) a Preços Correntes - 2005 a 2008

\begin{tabular}{|l|r|r|r|r|}
\hline \multirow{2}{*}{ Setor Econômicos } & \multicolumn{3}{|c|}{ Anos Bases } \\
\cline { 2 - 5 } & 2005 & 2006 & 2007 & 2008 \\
\hline Valor adicionado bruto da Agropecuária & 9.753 & 11.674 & 8.027 & 9.499 \\
\hline Valor adicionado bruto da Indústria & 82.304 & 88.049 & 105.109 & 112.823 \\
\hline Valor adicionado bruto dos Serviços & 255.847 & 239.050 & 272.732 & 299.481 \\
\hline Impostos sobre produtos liquidos de subsidios a preços correntes & 49.469 & 53.117 & 57.171 & 68.481 \\
\hline Total PIB a preços correntes & 397.373 & 391.890 & 443.039 & 490.284 \\
\hline
\end{tabular}

Fonte: Adaptado de informações Brasil (2014).

Conforme Lins (2009), apud Seabra (2008), as atividades do setor de serviços, particularmente o turismo, respondem por grande parte do crescimento urbano.

\section{Conclusão}

O processo de desenvolvimento dos espaços forma-se através das interações entre os objetos e o sistema de ações, sendo que Gramado em seu processo histórico passou por transformações que levaram a cidade a criar uma nova realidade. A globalização trouxe novas formas espaciais onde os atores hegemônicos intervêm cada vez mais nos espaços, alterando e reordenando os territórios e gerando perda de identidade local. Neste caso algumas regiões perderam com as macrodecisões e outras ganharam, mas, especificamente na situação da cidade de Gramado houve um ganho, pois esta tinha sua economia diversificada.

De acordo com Tomazzoni (2009), estudos confirmam que a razão do crescimento de 107 municípios gaúchos que dobraram o PIB nos últimos dez anos foi a aposta na diversificação produtiva, alternando atividades do setor primário com turismo e industrialização.

Com a estabilização da economia a cidade de Gramado, em primeiro lugar, descobriu que tinham uma grande vocação para o turismo, a partir das ideias empreendedoras de agentes públicos e privados, conseguiu tornar-se um dos 
principais destinos de turismo do Brasil, estando entre os 65 destinos indutores conforme o Ministério do Turismo. No entanto isto só foi possível graças à grande diversificação que a economia local tinha, entre o turismo e a indústria de calçados. Hoje a cidade tem como principal atividade o turismo, geradora de renda e de emprego a comunidade, além de integrar atores públicos e privados no seu desenvolvimento, evidencia esta a grande oferta de atrativos que a cidade possui e de eventos turísticos sendo realizados anualmente. No entanto foi constatado durante a pesquisa que ainda existem alternativas econômicas que estão crescendo cada vez mais na cidade e que ainda podem ser grandes apostas econômicas como as indústrias de metalúrgica e de móveis.

\section{Referências}

BOULLÓN, R. C. Planejamento do espaço turístico. Bauru: Edusc, 2002.

BRANDÃO, C. A. Revista Paranaense de Desenvolvimento, Curitiba, n. 107, p. 57-76, jul./dez. 2004.

BRASIL, Informações. PIB a preços correntes. Disponível em:

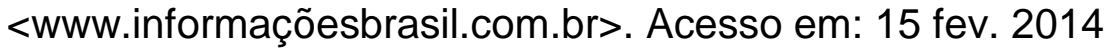

CRUZ, Rita de Cassia. Políticas de turismo e território. São Paulo: Contexto, 2000.

DAROS, Marília. Colonização: as etnias formativas de Gramado. In: Gramado Site. Disponível em <http://gramadosite.com.br/cgi/cultura/mariliadaros/id:26870/imprimir:1 >. Acesso em: 20 fev.2012.

DE LA TORRE, Francisco. Agência de Viagens e transporte. São Paulo: Rocca, 2003.

FEE. Fundação de Economia e Estatística. Valor Adicionado Bruto a Preços Básicos. 2014. Dados. Disponível em: <http://www.fee.rs.gov.br/>. Acesso em: 1jan. 2014.

HEIDRICH, Álvaro Luiz. Território, integração socioespacial, região, fragmentação e exclusão social. In: RIBAS, A. D.; SPOSITO, E. S.; SAQUET, M. A. (Orgs.). Território e desenvolvimento: diferentes abordagens. Francisco Beltrão: Unioeste, 2004. p. 37-66. 
KNAFOU, R. Turismo e território. Para um enfoque científico do turismo. In: RODRIGUES, A. B. et al. (Org.). Turismo e Geografia: reflexões teóricas e enfoques regionais. São Paulo: Hucitec, 2001.

LINS, Hoyêdo Nunes. Economia Regional e Urbana. Florianópolis: Departamento de Ciências - UFSC, 2009.

MACADAR, Jaime Adrian Moron; MACADAR, Beky Moron. Proposta de uma Modelo de Análise do valor de ativos estratégicos. Revista Brasileira de Estratégias, Curitiba, v. 6, n. 2, p.193-2009, 2013.

OLIVEIRA, M. H.; MEDEIROS, L. A. R. Panorama da indústria calçadista brasileira e o segmento de tênis. Rio de Janeiro: BNDES Setorial - Calçados, 1995.

PERROUX, F. A economia do século XX. Lisboa: Herder, 1967.

PETROCCHI. M. Gestão de polos turísticos. São Paulo: Futura, 2001.

ROSE, Alexandre T. de. Turismo: planejamento e marketing: aplicação da matriz de portfólio para destinações turísticas. São Paulo: Malone, 2002.

RUSCHMANN, D. Turismo e planejamento sustentável: a proteção do meio ambiente. São Paulo: Papirus, 1999.

SANTOS, Milton. O Brasil: território e sociedade no início do século XXI. Rio de Janeiro: Record, 2001.

SEABRA, Fernando. Contabilidade Social. Florianópolis: UFSC, 2008

SUERTEGARAY, Dirce Maria Antunes. Espaço Geográfico uno e múltiplo. Scripta Nova, n. 93, 15 jul. 2001.

TOMAZZONI, Edegar Luis. Turismo e desenvolvimento regional: dimensões, elementos e indicadores. Caxias do Sul: Educs, 2009. 